\title{
Lei e ordem nas Minas Gerais \\ formas de adaptação e de transgressão na esfera fiscal, 1700-1733
}

\section{Law and order in the District of Minas Gerais}

fiscal policies, bargaining and confrontation politics, 1700-1733

\author{
Vera alice Cardoso SiLVA \\ Professora Titular do Departamento de Ciência Política \\ Universidade Federal de Minas Gerais \\ vecar@fafich.ufmg,br
}

RESUMO 0 ensaio focaliza dois tipos de estratégia utilizados pelos habitantes da Capitania de Minas Gerais para lidar com a política fiscal do governo português, a saber, a adaptação, que se efetivava por meio de negociações com as autoridades coloniais, e a transgressão, que assumiu a forma da sublevação ou forma ilegal de sonegação do imposto do ouro. O período histórico coberto vai de 1700 a 1733.

Palavras-chave Capitania de Minas Gerais, política fiscal portuguesa, formas de oposição e de resistência política.

ABSTRACT The essay focus on two patterns of social and political reactions to the fiscal policy of the Portuguese government adopted by the population of the District of Minas Gerais during the first three decades of the eighteenth century. Such patterns are identified as the bargaining and the confrontation strategies, the latter including the options of insurrection and illegal behavior.

Artigo recebido em: setembro/2008. Autora convidada. 
Keywords District of Minas Gerais, Portuguese fiscal policy, bargaining and confrontation politics.

\section{Introdução}

Já são bem conhecidas as razões que levaram o governo português a implantar estrutura administrativa e judicial separada para a região das Minas Gerais, no início do século XVIII. A manutenção da ordem pública e a gestão rotineira da concessão de direitos de lavra e da cobrança de impostos sobre a extração do ouro revelaram-se insuficientes e ineficazes quando centralizadas, primeiro na jurisdição de autoridades sediadas no Rio de J aneiro, depois na de São Paulo, à medida que crescia a população na região das minas e aumentava o volume da produção de ouro. ${ }^{1}$

0 interesse do governo português sobre esta parte de seu domínio colonial sempre foi bem claro, isto é, garantir o máximo de ganho financeiro por meio da cobrança de tributos sobre a mineração e o pleno controle do comércio do ouro. Não pretendia o controle direto da extração, exceto no que se referia ao registro da concessão de direitos de lavra, por meio do qual os administradores dos negócios da Coroa tomavam conhecimento do rol de empreendedores privados e de sua capacidade de investimento. Tal capacidade era então medida pela disponibilidade de equipamentos para promover as obras necessárias à operação das minas e ao plantel de escravos reservados para esta atividade. ${ }^{2}$

Paralelamente, ao governo português interessava, também, controlar o comércio necessário como atividade de apoio à economia da mineração, à medida que esta se tornava empreendimento consolidado e especializado na região. Note-se que, também no que concernia à economia complementar à mineração, a saber, o comércio e a prestação de serviços diversos, a preocupação dos administradores portugueses era predominantemente fiscal. Todos os comerciantes e oficiais mecânicos - tanoeiros, marceneiros, ourives, ferreiros, alfaiates, artesãos diversos - eram obrigados a pagar taxas para exercer a profissão. Os itens comerciados que fossem importados pagavam tributos de valor variado para entrar na região das minas. Os fabricados dentro da Capitania também eram taxad os. ${ }^{3} \mathrm{Em}$ tal contexto, um governo distante do local onde viviam, consumiam e trabalhavam os súdi-

1 Coelho, J osé J oão Teixeira. Instrução para o governo da Capitania de Minas Gerais. Belo Horizonte: Fundação J oão Pinheiro - Centro de Estudos Históricos e Culturais (Coleção Mineiriana - Série Clássicos), 1994, capítulos 9 e 10.

2 Sobre a estrutura da administração fazendária no período colonial, ver Carmen Lúcia de Azevedo, "Administração fazendária". In Salgado, Graça, coordenadora. Fiscais e Meirinhos: a administração no Brasil colonial. Rio de J aneiro: Nova Fronteira, 1985, 83-96.

3 Coelho, J osé J oão Teixeira. Instrução, capítulos 14 ao 24; Souza, Laura de Mello e. Desclassificados do ouro. A pobreza mineira no século XVIII. Rio de J aneiro: Graal, 1982, especialmente capítulos 2 e 3. 
tos que deviam pagar impostos e taxas ficava limitado em sua capacidade disciplinadora, que devia ser exercida dia a dia.

Do início do século até 1720, quando o governo português decidiu instituir a Capitania de Minas Gerais como jurisdição administrativa e judicial separada, a instabilidade social e política prevaleceu na região. As lutas armadas que opuseram grupos de indivíduos que vinham da Capitania de São Paulo - os paulistas - e imigrantes portugueses, cada grupo pretendendo estabelecer seu próprio governo sobre as minas e sobre a população que ali se congregava, serviram para alertar o rei de que seu domínio senhorial seria seriamente contestado se ali não se implantasse governo direto e visível para todos, isto é, para brasileiros/paulistas e súditos portugueses. ${ }^{4}$

Mas, a criação da Capitania de Minas Gerais era apenas o requisito inicial formal para a efetividade do domínio pleno e estável do governo português sobre a economia da mineração. A efetividade de tal domínio dependia da adesão dos habitantes das Minas Gerais às regras por meio das quais os objetivos fiscalistas do governo português de fato se realizariam. No entanto, na perspectiva das relações políticas, a criação da Capitania foi a condição que possibilitou a presença direta e cotidiana do poder regulador e fiscalizador da metrópole, o que certamente tornava mais real a dimensão da dominação sobre os súditos da sociedade da mineração.

\section{Economia do dinheiro e conflitos fiscais}

No processo histórico de ocupação da região, a motivação de ambos os lados - súditos e governo português - era a mesma e muito forte, isto é, acumular riqueza que vinha da descoberta e exploração de bens minerais, primeiro o ouro, depois o diamante. Destes, o ouro era componente típico da dimensão financeira do mercantilismo. No século XVIII brasileiro, sua exploração deu origem a uma efetiva economia do dinheiro na colônia, induzindo, na região das minas, o surgimento de conflito eminentemente moderno, isto é, aquele que opõe governado e governante na esfera da regulamentação tributária.

A história política da região das Minas Gerais, ao longo de todo o século XVIII, pode ser predominantemente referida à dinâmica de conflitos fiscais. Mas, as formas de enfrentamento e resolução de tais conflitos variaram. Em documentos e relatos de contemporâneos, verifica-se que o governo português tinha preferência por formas mais rigorosas e burocratizadas de controle da produção e da tributação. No entanto, defrontava-se com súditos que não se sujeitavam ao controle proposto sem reação.

4 Vasconcelos, Diogo de. História antiga de Minas Gerais. Belo Horizonte: Itatiaia, 1999, quarta parte. 
Em tal contexto, é possível identificar dois tipos de estratégia utilizados pelos governados face ao poder de domínio investido nas autoridades portuguesas locais. Em alguns casos, buscavam adaptar-se a esse poder. Em outras instâncias, adotavam formas de transgressão às normas emanadas do governo metropolitano.

A opção pela adaptação revelava-se, predominantemente, em negociações entabuladas entre membros da elite econômica e política da Capitania, que, nesse contexto, poderiam ser identificados como lado brasileiro da contenda, e governadores nomeados pelo rei, que falavam e decidiam em seu nome, constituindo, assim, o lado português do diálogo. ${ }^{5}$

A opção pela transgressão, por sua vez, está associada à explícita desobediência às normas prescritas pela autoridade real que, na forma extrema, manifestou-se em sublevações contra o governo português. Entre essas, são bem conhecidas a de 1720 e a de 1789.

Neste ensaio, são comentadas instâncias dos dois tipos de estratégia, que ocorreram nas três primeiras décadas do século XVIII, período que inclui a criação formal da Capitania de Minas Gerais e a fase inicial da consolidação da sociedade da mineração, que, em boa medida, confunde-se com a chamada sociedade do barroco.

\section{Estratégias de adaptação à política fiscal portuguesa}

Levando-se em conta a natureza das relações súdito-rei em regimes absolutistas, no que se refere à prerrogativa real de impor tributos, não se prevê que haja negociações com o governado, que se justificassem pela possibilidade de desobediência do súdito à ordem real. Tal desobediência, de fato sempre possível, seria considerada, segundo a racionalidade desse tipo de regime, como sublevação e, como tal, seria reprimida como crime de lesa majestade. No entanto, verifica-se que, na Capitania das Minas Gerais, ocorriam negociações entre os membros da elite econômica local - concessionários de direitos de lavra, fazendeiros e comerciantes - e os governadores, prepostos do rei, concernentes ao modo de cobrança do tributo devido sobre o montante do ouro extraído. Em princípio, cabia à fazenda real um quinto do que era produzido. A forma preferida pelo rei para o registro da produção e recolhimento do tributo devido foi, desde o início da economia da mineração na colônia, o sistema das casas de fundição. Tal sistema permitia coibir melhor a sonegação, pois apenas o ouro fundido e quintado, ou seja, que trazia a marca real, tinha curso legal. ${ }^{6}$

5 J osé J oão Teixeira Coelho dá notícia de várias juntas, ou seja, reuniões em geral promovidas por governadores que buscavam obter apoio da elite econômica e política da Capitania para medidas impopulares, especialmente na esfera tributária. Instrução, especialmente capítulos 10 e 11.

6 Vasconcelos, Diogo de. História média de Minas Gerais, Belo Horizonte: Itatiaia, 1999, segunda parte; Coelho, J osé J oão Teixeira. Instrução, capítulo 12. 
Mas, esta forma de se organizar o aspecto oficial da economia do ouro não contava com o apoio dos mineradores. Independentemente de qualquer desígnio de sonegação, sabiam eles que o sistema de cobrança pela casa de fundição incidia mais negativamente sobre seu lucro, pois o quinto seria forçosamente recolhido na instituição oficial. Além disso, sabia-se que as balanças utilizadas podiam ser adulteradas em prejuízo dos mineradores. Além do mais, o quinto seria calculado sem levar em conta variações no valor da produção, que afetassem cada minerador individualmente e o coletivo dos agentes econômicos. Cada minerador defrontavase com o problema da irregularidade dos veios auríferos, conhecendo a dificuldade de se prever, a mais longo prazo, a rentabilidade do negócio. Por isto, preferia negociar o valor do tributo a ser pago anualmente pelo conjunto dos detentores dos direitos de lavra. Também parecia melhor 0 sistema de cobrança pelo princípio da capitação, ou seja, o pagamento do tributo calculado pelo número de escravos empregados na mineração, desde que se admitisse avaliação dos casos em que o trabalho investido não correspondesse a volume de produção que compensasse o valor a ser descontado da produção como contribuição compulsória para a fazenda real.

Independentemente das preferências dos mineradores, as instruções reais para os governadores eram geralmente bem específicas: deviam implantar as casas de fundição e cobrar o quinto sobre o ouro em pó entregue para a fundição. Mas, defrontando-se com a resistência da elite local, alguns governadores, como Pedro de Almeida, Conde de Assumar, e seus sucessores imediatos, Lourenço de Almeida e André de Melo e Castro, Conde de Galveas, cederam temporariamente à pressão dos mineradores e não implantaram logo o sistema das casas de fundição. Em tal contexto, o conflito fiscal parecia sanado, mas voltava à tona sempre que o governador decidia-se a impor o que lhe era comandado pelo rei.

A reação dos súditos à implantação de forma de cobrança do quinto que não os beneficiava, podia assumir, então, a forma de transgressão, fosse esta radical, como sucedeu em junho de 1720 , com a sublevação que ficou conhecida como Revolta de Felipe dos Santos, ou como ilegalidade, como se deu no caso da organização de quadrilha de moedeiros falsos, descobertos, presos e julgados em 1732.

Note-se que a sublevação de 1720 foi motivada pela decisão do governador, Conde de Assumar, de fixar a data de implantação das casas de fundição, rompendo, assim o "acordo" que até então havia legitimado o sistema da finta, isto é, do pagamento do tributo anual segundo valor previamente combinado entre a população da Capitania e o governo português. Em 1720, prevalecia o trato de pagamento de 30 arrobas de ouro, por ano, que era resultado de negociação entre as duas partes - mineradores e 
governador - visando a aumentar o montante de 25 arrobas, anteriormente acordado. ${ }^{7}$

O sistema da capitação continha aspectos econômicos e políticos mais complexos, pois representava concepção de política fiscal que afetava toda a organização econômica da Capitania. Não tratava a mineração como setor separado das demais atividades que eram subsidiárias da economia principal. De fato, tal sistema previa a cobrança de tributos sobre a propriedade de escravos, independentemente do tipo de trabalho que praticassem, bem como sobre o exercício de ofícios e sobre as atividades de comércio. $\mathrm{Na}$ sua lógica própria, esta concepção de política tributária não levava em conta ciclos produtivos. Se a dinâmica da economia fosse levada em conta, tornava-se forçoso reconhecer períodos de retração na extração do ouro que, certamente, afetavam as atividades subsidiárias e a capacidade contributiva dos agentes econômicos. Também não permitia tratar de modo diferenciado os vários tipos de agentes econômicos. Na economia da mineração havia os grandes e os pequenos mineradores. Na estrutura do comércio da Capitania, havia as lojas, estabelecimentos maiores, e as vendas. Nos ofícios, havia as corporações estabelecidas, com clientelas definidas, e os biscateiros. Mas, acima e além das diferenças, todos ficavam comprometidos com o pagamento do tributo do ouro. Nesse sistema, o valor da contribuição por item taxado era fixado por meio de estimativas do valor geral da produção da Capitania, uma espécie de cálculo de seu produto interno bruto, tarefa que ficava a cargo de funcionários portugueses e sempre dava origem a insatisfação dos contribuintes.

0 certo é que, qualquer que fosse o sistema de cobrança do imposto do ouro, a preocupação da população da Capitania com a disponibilidade de dinheiro para pagar impostos era constante.

O sentimento de opressão fiscal, experimentado pelos súditos, tendia a aumentar quando eram obrigados a contribuir com mais dinheiro para a fazenda real em ocasiões especiais. Na segunda metade da década de 1720, por exemplo, o dote de príncipe e de princesa portugueses, que se casaram com filhos da realeza espanhola, foi formado por "doações" dos súditos de todas as partes do império português. Na Capitania de Minas Gerais, a população adotou estratégia de adaptação face a mais essa expressão da vorac idade extrativa da Coroa portuguesa. Não criou empecilhos ao recolhimento da contribuição, mesmo porque esse tipo de prática, por ocasião de casamentos de filhos da casa reinante, era comum em muitos reinados, sendo legitimada por tradição. Mas, através de negociações conduzidas pelos oficiais das Câmaras Municipais das sete vilas então existentes, combinaram com o governador o montante da contribuição (125

7 Veiga, J osé Xavier da. Efemérides Mineiras. Belo Horizonte: Fundação J oão Pinheiro - Centro de Estudos Históricos e Culturais, 1998, 2 vols., efemérides de 11.02 .1719 e de 28.06.1720. 
arrobas de ouro) e o prazo da totalização do pagamento (seis anos). Caberia à Câmara de cada vila recolher a doação, cujo valor variou por vila, segundo o tamanho da população e a capacidade contributiva dos estratos sociais identificados: mineradores, fazendeiros, grandes e pequenos comerciantes, artesãos dos diversos ofícios. Combinou-se até que cada Câmara trataria de identificar, em sua jurisdição, moradores que tinham herança a receber, que também deveriam ser chamados a participar do esforço coletivo. ${ }^{8}$

Muitos anos depois, os súditos portugueses foram obrigados a contribuir para o fundo destinado a financiar a reconstrução de Lisboa, parcialmente destruída por um terremoto. 0 tributo especial, então chamado de subsídio voluntário, deveria ser cobrado pelo período de dez anos, a partir de 1756. De novo os moradores da Capitania submeteram-se, sem reclamações públicas, à imposição real. Mas, continuando o tributo a ser cobrado completado o decênio de sua vigência, os oficiais das Câmaras das vilas mineiras declararam ao governador que não mais coletariam a contribuição, pois tal medida tornara-se abusiva, segundo os termos da ordem régia que a impusera. Em 1766, diante desse tipo de manifestação pública, o governador, Conde de Valadares, seguindo instruções do governo português, buscou apoio entre os maiorais da Capitania para a continuação do pagamento por mais dez anos. Mediante concessões na cobrança de outros tributos, que aceitou que fossem passados para o controle das Câmaras Municipais, conseguiu obter apoio da elite política e econômica local para a prorrogação da cobrança do dito subsídio por mais dez anos. ${ }^{9}$

Verifica-se, então, que a população da Capitania estava, em geral, atenta ao peso dos impostos e buscava limitar os efeitos perversos da voracidade fiscal portuguesa sobre seus negócios e patrimônio.

No que se refere à cobrança do quinto do ouro, a implantação do sistema das casas de fundição continuou a ser fonte de tensão permanente entre os súditos da Capitania de Minas Gerais e o governo português, durante todo o século XVIII. A insatisfação foi gradualmente aumentando à medida que diminuía o volume de ouro extraído das minas já descobertas e minguava a ocorrência de novos achados. A necessidade de aumentar o investimento em tecnologia para a exploração do ouro em minas subterrâneas esbarrava no empobrecimento gradual dos mineradores que permaneceram na Capitania. ${ }^{10}$

Em tal contexto, com a persistência da orientação fiscalista do governo português, tornava-se realmente limitada a eficácia da estratégia de negociação do pagamento de tributos sob forma que beneficiasse os habitantes de

8 Veiga, J osé Xavier da. Efemérides, efeméride de 12.04.1727. 0 governador era Lourenço de Almeida. As sete vilas com Câmaras próprias eram Vila de Nossa Senhora do Carmo, Vila Rica, Vila Real de Sabará, Vila do Príncipe, Vila de São J oão Del Rei, Vila de São J osé e Vila Nova da Rainha.

9 Coelho, J osé J oão Teixeira. Instrução, capítulo 11, item 5: Do governo do Conde de Valadares.

10 Coelho, J osé J oão Teixeira. Instrução, capítulo 13; Souza, Laura de Mello e. Desclassificados, capítulo 1. 
Minas Gerais. Se o peso dos tributos passasse a ser visto como insuportável ou abusivo, a transgressão, para muitos, podia aparecer como opção, quer no plano individual - a fabricação de dinheiro falso, por exemplo - quer no plano coletivo - a sublevação, por exemplo.

De todo modo, pode-se concluir que o aspecto fiscal do governo português nas Minas Gerais foi sempre foco de tensões políticas e fonte de insatisfação entre os governados.

\section{Estratégias de transgressão face à política fiscal portuguesa}

A transgressão, entendida como tipo de comportamento político que ocorre em sistemas políticos já institucionalizados, isto é, que já funcionam com algum grau de eficácia e previsibilidade na aplicação das leis e no controle dos governados, expressa oposição e resistência à ordem jurídica e administrativa vigente. Pode assumir conotação especificamente política quando dá origem a movimentos públicos de contestação às leis e aos governantes que as formulam e as aplicam. Este foi, por exemplo, o caso das sublevações contra o governo colonial na região das minas.

Mas, a transgressão pode expressar-se, também, como desobediência às leis por parte de indivíduos que não têm a intenção de dar sentido político à ilegalidade que cometam. Se e quando descobertos, são tratados como criminosos pelas autoridades, e não como subversivos ou traidores, como é o caso da categorização política dos que aderem à transgressão que assume a forma insurrecional de contestação à ordem vigente.

Ambas as formas de transgressão, se não controladas ou neutralizadas, introduzem elementos de instabilidade no convívio social que diminuem a legitimidade do governo estabelecido.

Nas três primeiras décadas do século XVIII, na região das Minas Gerais, o governo português defrontou-se com os dois tipos de transgressão em formas de associação de súditos que tinham por referência a política fiscal. 0 modo como lidou com cada um oferece elementos para esclarecedora reflexão sobre a natureza das relações entre governados e governantes na sociedade da mineração.

\section{Transgressão como sublevação}

0 movimento que ficou registrado como Revolta de Felipe dos Santos apresenta aspectos valiosos para se compreender como se dava a política em um sistema de governo absolutista, isto é, no qual o soberano concedia direito de fala e de petição ao governado, mas não Ihe reconhecia o direito de representação autônoma na esfera da produção de leis e diretivas de governo. 
A associação dos moradores de Vila Rica, em junho de 1720, em um movimento de insurreição, teve como motivação principal o anúncio feito pelo governador Pedro de Almeida, Conde de Assumar, da implantação do sistema das casas de fundição a partir de 1721. Na falta de instituições mediadoras dos interesses dos governados, quando o governante não se dispunha à negociação restava apenas a alternativa entre a obediência passiva ou a sublevação.

Insurgindo-se contra o sistema das casas de fundição, os homens livres da Capitania rebelavam-se, também, contra outras características do governo português, que consideravam intoleráveis. No auge da rebelião, os revoltosos entregaram ao governador, em 2 de julho de 1720, um termo de demandas, que especificava todos os agravos que desejavam ver corrigidos e as mudanças que viam como necessárias para a instituição de um governo justo. A lista continha quatorze pontos. Faz sentido apresentar todas as demandas então feitas, pois demonstram, cristalinamente, o sentimento de opressão fiscal que motivava os revoltosos.

1. Recusa de casas de fundição, cunhos e moedas.

2. Permanência do contrato vigente para a fixação do valor devido como imposto do ouro (sistema de finta).

3. Revisão dos procedimentos de cobrança de taxas sobre mercadorias no Registro de Borda do Campo (sugeriam os sublevados que se impusesse a regra da declaração escrita do bem que entrava na Capitania, estabelecendo-se o princípio geral de pagamento do valor de meia oitava por saco, meia pataca por produto molhado e oitava e meia por negro novo).

4. Manutenção do valor de 30 arrobas como quinto do ouro; o valor total, se não fosse atingido com o produto da mineração, deveria ser completado com contribuições de lojas e vendas (cada estabelecimento sendo taxado em cinco oitavas de ouro) e por negro possuído por todos os habitantes da Capitania (oitava e meia por cabeça).

5. Avaliações de escravos e de bens imóveis, no caso de arrematação de propriedade para quitação de dívidas, deveriam ser feitas por "dois louvados de sã consciência", isto é, por homens honestos, de modo a evitar a subestimação dos bens, em prejuízo do devedor.

6. Fixação de tabelas de remuneração de escrivões, tabeliões, meirinhos e alcaides, a ser feita pelo governador do Rio de J aneiro, com o objetivo de coibir "excessos tão exorbitantes", observados na rotina da administração na região das minas.

7. Padronização de pesos e medidas para a aferição de balanças usadas nos negócios locais.

8. Fixação oficial do valor de taxas cobradas por senviços públicos prestados, por exemplo, por escrivões (da Câmara Municipal, da Almotaçaria). 
9. Fixação de valor máximo de meia pataca por produto cuja comercialização dependesse da autorização do almotacé, ou seja, do funcionário da Câmara que fiscalizava o comércio local.

10. Fixação de limites para o poder normativo dos "senhores do Senado [da Câmara]" que, segundo os sublevados, eram responsáveis por "condenações exorbitantes ao povo", não controlados por regimento ou lei (citavam-se problemas específicos: a transferência do encargo de construção de ruas e calçadas para os moradores; tal atribuição, ao ver dos moradores, deveria ser da Câmara Municipal; a concessão que deveria ser anual, e não mensal, de licenças para o exercício de negócios e ofícios; o financiamento da alimentação dos soldados das tropas pagas (dragões) pelo poder público ou por eles mesmos, e não "pelo povo").

11. Garantia de que os contratadores da cobrança de dízimos (impostos diversos devidos pelos comerciantes e prestadores de serviços) respeitassem os prazos acordados para seu pagamento.

12. Contenção do poder arbitrário de autoridades nomeadas pelo rei (chamados de ministros), de modo a se garantir que não produzissem "despachos violentos", que causavam "vexações ao povo".

13. Distribuição do pagamento das custas de diligências requeridas por processos judiciais entre todos os envolvidos, recomendando-se que o perdão das mesmas fosse sempre pedido às autoridades.

Porfim, e não menos importante, os sublevados pediam o perdão para todos os revoltosos, dada a justeza de sua causa. ${ }^{11}$

Note-se que as demandas tinham um foco dominante, isto é, buscavam apontar o caráter arbitrário de regras e leis do governo português que se traduziam, aos olhos dos governados, predominantemente como opressão financeira.

A forma como regras e instruções normativas eram escritas e interpretadas pelos funcionários do rei e pelos que eram por estes nomeados para o exercício rotineiro da administração e fiscalização dos negócios públicos dava margem a muita arbitrariedade em todos os aspectos da relação entre governante e governado. Sob este prisma, a lista de demandas é exemplar: aponta fraudes na avaliação de bens particulares a serem leiloados para pagamento de dívidas, nas balanças que pesavam ouro e outras mercadorias, na cobrança de taxas sobre o comércio de produtos e sobre o exercício dos ofícios; a exorbitância das taxas cobradas pela emissão de documentos públicos necessários para transações diversas. Denunciava,

11 Veiga, J osé Xavier da. Efemérides, efeméride de 2.07.1720. 
também, a truculência com que altas autoridades da administração colonial exerciam seus cargos.

Ao apresentar ao governador suas queixas e reivindicações, os sublevados utilizaram a noção de povo, no sentido medieval de população submetida a um soberano que era visto como superior maior, portanto devendo ser respeitado, mas investido do dever moral de proteger o súdito e de zelar para que fosse tratado com equanimidade pelos seus superiores. Tem-se, portanto, nas sublevações que ocorreram na Capitania, a manifestação do problema da legitimação do poder soberano. Sob o absolutismo, esta condição do governo estável dependia do sentimento de justiça que cada súdito experimentasse com relação ao conteúdo das leis que o submetiam e à correção dos procedimentos dos funcionários do rei.

Do lado do governante, observa-se, no enfrentamento da sublevação de 1720, o modo ambíguo de exercer o poder político num contexto em que as autoridades coloniais se defrontaram com súditos que agiam como homens livres. De fato, a sociedade da mineração foi gradualmente criando condições cada vez mais promissoras para a experiência da liberdade política. Confrontado com a força popular da revolta, o governador Pedro de Almeida publicamente deferiu todos os pedidos dos sublevados. Estes apareceram, então, nesse momento, como vitoriosos. Mas, no seu contato com o governo central, o governador comunicava que estava atento à promoção do que fosse necessário "para restabelecer o que [tivesse ficado] arruinado da parte de Sua Majestade". Tal disposição de preservar o interesse real, "contra o povo", acabou resultando na prisão e julgamento posteriores de líderes do movimento e, pouco tempo depois, já sob o governo de Lourenço de Almeida, que sucedeu o Conde de Assumar, na implantação do sistema das casas de fundição. ${ }^{12}$

Não se tem notícia de que, nesses primeiros anos de governo sediado na região das minas, as arbitrariedades na cobrança de taxas e tributos ou nas decisões e sentenças das autoridades reais tenham sido coibidas. Mas, na Instrução para o governo da Capitania de Minas Gerais, escrita no final da década de 1780 pelo funcionário da Coroa J osé J oão Teixeira Coelho, encontram-se muitas referências negativas ao modo de proceder de ocupantes de altos cargos, entre elas notícias de práticas de corrupção e favorecimentos indevidos, situações que despertavam repúdio da população da terra e do próprio Teixeira Coelho. ${ }^{13}$

Apesar de a repressão aos sublevados de 1720 ter sido localizada, as causas que defenderam em nome de toda a população não saíram vitorio-

12 Veiga, J osé Xavier da. Efemérides, efemérides de 2.08.1720 e de 26.03.1721.

13 Coelho, J osé J oão Teixeira. Instrução, capítulo 7. Nele, o funcionário descreveu o que classificou de abusos cometidos por autoridades da administração portuguesa. Terminou a enumeração deles com um "catálogo de algumas determinações reais que devem saber os governadores", que pode ser lida como um "manual do bom governante". 
sas. A truculência do governo português tendeu a aumentar, à medida que diminuíam a capacidade produtiva da mineração e o volume de dinheiro em circulação na Capitania.

\section{falsos. \\ Transgressão como opção pelo crime: a quadrilha de moedeiros}

Uma forma difundida e não diretamente política de transgressão é a opção pelo crime como meio de burlar a lei com o objetivo de obter enriquecimento pessoal. Durante a vigência do sistema das casas de fundição, esta escolha reuniu um grupo de pessoas gradas das Capitanias do Rio de J aneiro e de Minas Gerais, que planejaram produzir e por em circulação dinheiro falso.

Em 1730, com a ajuda de artífices especializados, os organizadores do negócio montaram uma fundição em rincão de difícil acesso em Minas Gerais, que funcionou durante dois anos, até ser descoberta pelas autoridades portuguesas. Note-se que as moedas produzidas eram mesmo de ouro. 0 que havia de ilegal, portanto falso, era o local da fabricação e 0 sinal da cunhagem. Dessa maneira, sonegava-se o pagamento do quinto, mas o ouro em pó adquiria a forma legal para circulação.

0 registro histórico desse caso indica que a "sociedade" estava em franca expansão quando foi desbaratada, em 1732, e que parceiro importante dela era parente do rei. Seu nome não é conhecido, mas os demais membros da quadrilha foram presos e julgados, tudo indica que grande rigor. Os artífices, ou seja, os que montaram e operavam a fábrica, pagaram o crime com a vida. Não há registro das penas aplicadas às pessoas gradas que haviam financiado o empreendimento, entre elas mineradores e grandes comerciantes. Todos buscavam, com esse tipo de crime, aumentar sua fortuna. ${ }^{14}$

Para lidar com este tipo de transgressão, 0 aparato judicial existente parecia ser suficiente. Mas, o caso tornou o governo português cauteloso, de tal modo que o rei deliberou, em 1733, substituir o sistema das casas de fundição pelo sistema de cobrança do imposto do ouro por meio da capitação e do que se chamava, então, de censo da indústria, expressão que denota o registro de todos os negócios e ofícios instalados na Capitania, com o objetivo de formar lista completa de contribuintes compulsórios.

O caso da quadrilha de moedeiros falsos mostra que os súditos reagiam à opressão fiscal de modo diferenciado: 0 interesse desse grupo era adquirir ou aumentar riqueza pessoal. Para isso, usava a própria estrutura normativa vigente em seu benefício. Por sua vez, os revoltosos de 1720,

14 Veiga, J osé Xavier da. E femérides, efemérides de 12.08.1732 e de 29.10.1733. 
entre os quais também se encontravam pessoas gradas da sociedade colonial, queriam mudar a ordem política vigente a partir da contestação armada, com reivindicações por reformas na administração que, a seu ver, beneficiariam o coletivo.

Ambas as formas de transgressão estavam destinadas ao fracasso no contexto colonial, pois o governo absolutista de orientação mercantilista não admitia nem fraude que debilitasse a fazenda real nem o reconhecimento do direito de expressão autônoma do governado, incluído aí o direito de oposição. Ainda seria necessário esperar mais de dois séculos pela efetivação do princípio da representação política do governado na constituição do poder soberano no Brasil.

Mas, não se pode concluir que as mudanças constitucionais que decorreram da independência política, no século XIX, e, mais tarde, da implantação do regime republicano, no século XX, tenham levado a soluções de conflitos fiscais plenamente satisfatórias para os governados, ou mesmo superado o sentimento de opressão fiscal que, segundo modos de expressão variados, tem feito parte da conturbada história das relações entre governados e governantes no Brasil, desde os tempos coloniais. 